\title{
Nephrotic Syndrome with Focal Segmental Glomerulosclerosis Induced by Intravitreal Injections of Vascular Endothelial Growth Factor Inhibitor
}

\author{
Kota Kakeshita, Tsutomu Koike, Teruhiko Imamura, Sayaka Murai, Hayato Fujioka, \\ Hidenori Yamazaki and Koichiro Kinugawa
}

\begin{abstract}
:
An 83-year-old woman with a 1-year history of scheduled intravitreal injection of vascular endothelial growth factor (VEGF) inhibitor (aflibercept) was diagnosed with nephrotic syndrome due to focal segmental glomerulosclerosis with histopathological findings of segmental infiltration of foam cells in the glomerular capillaries. Her nephrotic syndrome improved immediately following the termination of aflibercept intravitreal injection without steroid therapy. Although widely used to treat ophthalmic diseases, we should keep in mind that even intravitreal injection of VEGF inhibitor, as opposed to systemic administration, can cause kidney injury.
\end{abstract}

Key words: aflibercept, proteinuria, podocyte, VEGF inhibitor

(Intern Med 59: 3051-3054, 2020)

(DOI: 10.2169/internalmedicine.5410-20)

\section{Introduction}

Vascular endothelial growth factor (VEGF) inhibitors suppress angiogenesis and are widely used as major anti-tumor agents. However, VEGF inhibitors also worsen systemic hypertension and proteinuria in general and cause thrombotic micro-angiopathy in severe cases by suppressing the activity of VEGF in the kidney (1).

VEGF inhibitors are presently administered via intravitreal injection to treat age-related macular degeneration. However, it was reported recently that VEGF inhibitors might induce renal toxicity even when administered via intravitreal injection (2).

We experienced a patient who suffered from nephrotic syndrome due to focal segmental glomerulosclerosis following the intravitreal injection of VEGF inhibitor for macular degeneration, which immediately normalized following the termination of VEGF inhibitor treatment without any intensive therapies, including steroid administration.

\section{Case Report}

\section{Before the renal biopsy}

An 83-year-old woman with a 1-year history of intravitreal administration of aflibercept, a VEGF inhibitor, for her age-related macular degeneration with choroidal neovascularization and retinal hemorrhaging was admitted to our institute with edema of the bilateral lower extremities as well as proteinuria (dipstick test $4+$ and $18.3 \mathrm{~g} / \mathrm{g}$ of creatinine), $2.5 \mathrm{~g} / \mathrm{dL}$ of serum albumin, and $1.1 \mathrm{mg} / \mathrm{dL}$ of serum creatinine, which was diagnosed as nephrotic syndrome. Six months before the admission, her serum albumin level had been $4.0 \mathrm{~g} / \mathrm{dL}$ and her creatinine level $0.63 \mathrm{mg} / \mathrm{dL}$. On admission, her blood pressure was $148 / 90 \mathrm{mmHg}$, despite the administration of irbesartan $100 \mathrm{mg} /$ day and amlodipine $2.5 \mathrm{mg} / \mathrm{day}$. Computed tomography showed slight bilateral pleural effusion and ascites without any anatomical findings. Other data of laboratory and urinary tests are shown in Table.

The Second Department of Internal Medicine, University of Toyama, Japan 
Table. Laboratory Data from the Kidney Biopsy.

\begin{tabular}{|c|c|}
\hline Laboratory test & Result \\
\hline \multicolumn{2}{|l|}{ Urinalysis } \\
\hline Urine specific gravity & 1.037 \\
\hline Urine protein & $(4+)$ \\
\hline Urine occult blood & $(-)$ \\
\hline \multicolumn{2}{|l|}{ Urine sedimentation } \\
\hline Red blood cells, /high-power field & $1-4$ \\
\hline White blood cells, /high-power field & $5-9$ \\
\hline Fatty casts, /low-power field & $<1$ \\
\hline Waxy casts, /low-power field & $1-9$ \\
\hline \multicolumn{2}{|l|}{ Complete blood cell counts } \\
\hline White blood cells, $/ \mu \mathrm{L}$ & 6,760 \\
\hline Red blood cells, $/ \mu \mathrm{L}$ & $407 \times 10^{4}$ \\
\hline Hemoglobin, g/dL & 13.1 \\
\hline Platelets, $/ \mu \mathrm{L}$ & $33.9 \times 10^{4}$ \\
\hline \multicolumn{2}{|l|}{ Serum chemistry } \\
\hline Total protein, g/dL & 4.7 \\
\hline Albumin, $\mathrm{g} / \mathrm{dL}$ & 1.8 \\
\hline AST, IU/L & 32 \\
\hline ALT, IU/L & 22 \\
\hline LDH, IU/L & 325 \\
\hline BUN, mg/dL & 21 \\
\hline Creatinine, $\mathrm{mg} / \mathrm{dL}$ & 1.42 \\
\hline Total cholesterol, $\mathrm{mg} / \mathrm{dL}$ & 248 \\
\hline LDL cholesterol, mg/dL & 124 \\
\hline HDL cholesterol, mg/dL & 45 \\
\hline Triglyceride, $\mathrm{mg} / \mathrm{dL}$ & 282 \\
\hline Sodium, $\mathrm{mEq} / \mathrm{L}$ & 141 \\
\hline Potassium, $\mathrm{mEq} / \mathrm{L}$ & 4.2 \\
\hline Chlorine, $\mathrm{mEq} / \mathrm{L}$ & 111 \\
\hline \multicolumn{2}{|l|}{ Serum immunological test } \\
\hline C-reactive protein, $\mathrm{mg} / \mathrm{dL}$ & 0.04 \\
\hline Immunoglobulin $\mathrm{G}, \mathrm{mg} / \mathrm{dL}$ & 590 \\
\hline Immunoglobulin $\mathrm{A}, \mathrm{mg} / \mathrm{dL}$ & 137 \\
\hline Immunoglobulin $\mathrm{M}, \mathrm{mg} / \mathrm{dL}$ & 56 \\
\hline Complement $3, \mathrm{mg} / \mathrm{dL}$ & 139.3 \\
\hline Complement $4, \mathrm{mg} / \mathrm{dL}$ & 52.0 \\
\hline $\mathrm{CH} 50, \mathrm{U} / \mathrm{mL}$ & $>60$ \\
\hline Antinuclear antibody & negative \\
\hline MPO-ANCA & negative \\
\hline PR3-ANCA & negative \\
\hline Anti-GBM antibody & negative \\
\hline
\end{tabular}

AST: aspartate aminotransferase, ALT: alanine aminotransferase, LDH: lactate dehydrogenase, BUN: blood urea nitrogen, LDL: low-density lipoprotein, HDL: high-density lipoprotein, CH50: 50\% hemolytic complement activity, PR3: proteinase 3, MPO: myeloperoxidase, ANCA: anti-neutrophil cytoplasmatic antibody, GBM: glomerular basement membrane

\section{The renal biopsy}

We performed a renal biopsy to further investigate the pathology of nephrotic syndrome and construct a therapeutic strategy and found 13 glomeruli using an optical microscope. Seven of the 13 showed global sclerosis. There were no specific findings in the other four glomeruli (Fig. 1A). However, the segmental infiltration of foam cells was found in the glomerular capillaries of two of those four glomeruli (arrowheads in Fig. 1B, C). Immunofluorescence staining showed no deposition of immunoglobulin or complements. Electron microscopy showed widespread effacement of podocyte foot process (Fig. 1D). Swelling of endothelial cells and widening of the subendothelial space were trivial, and there was no diffuse endothelial cell injury. We finally diagnosed her with nephrotic syndrome due to focal segmental glomerulosclerosis (FSGS) based on the clinical and histopathological findings.

\section{After the renal biopsy}

During hospitalization, her proteinuria (gray bars) was ameliorated, and her serum albumin level (red line) increased gradually without any specific interventions (Fig. 2). We suspected renal toxicity due to aflibercept and decided to terminate the scheduled intravitreal injection. After discharge, the proteinuria normalized, accompanied by improvement in her serum albumin level without steroid therapy.

\section{Discussion}

We experienced an 83-year-old woman with nephrotic syndrome due to FSGS that was normalized immediately after the termination of the scheduled intravitreal injection of aflibercept, a VEGF inhibitor, without any intervention, including steroid therapy.

\section{VEGF inhibitors}

VEGF is a cytokine that activates angiogenesis by affecting endothelial cells. VEGF inhibitors suppress the activity of VEGF and are widely used as anti-tumor agents. Furthermore, they are injected into the vitreous to treat age-related macular degeneration and diabetic macular edema by suppressing angiogenesis at the choroid (3).

Aflibercept is a genetic recombinant protein composed of the binding domains of two human VEGF receptors fused with the Fc region of human immunoglobulin gamma 1 and suppresses abnormal angiogenesis by inhibiting the activity of VEGF (4).

\section{Nephrotoxicity induced by VEGF inhibitors}

Systemically administered VEGF inhibitor is known to injure the kidney and cause proteinuria dose-dependently (5). Among severe cases, 70\% show thrombotic microangiopathy (mainly caused by VEGF direct suppressors including aflibercept), and 30\% show minimal change disease or FSGS (mainly caused by VEGF receptor blockers and multitargeted tyrosine kinase inhibiters) (6). Of note, aflibercept caused FSGS in this case.

In the general glomerulus, the glomerular structure and function are maintained by the complex signal interaction between the podocyte secreting VEGF and the endothelial cells expressing the VEGF receptor. When the VEGF signal cascade is inhibited, the injury of endothelial cells results in 


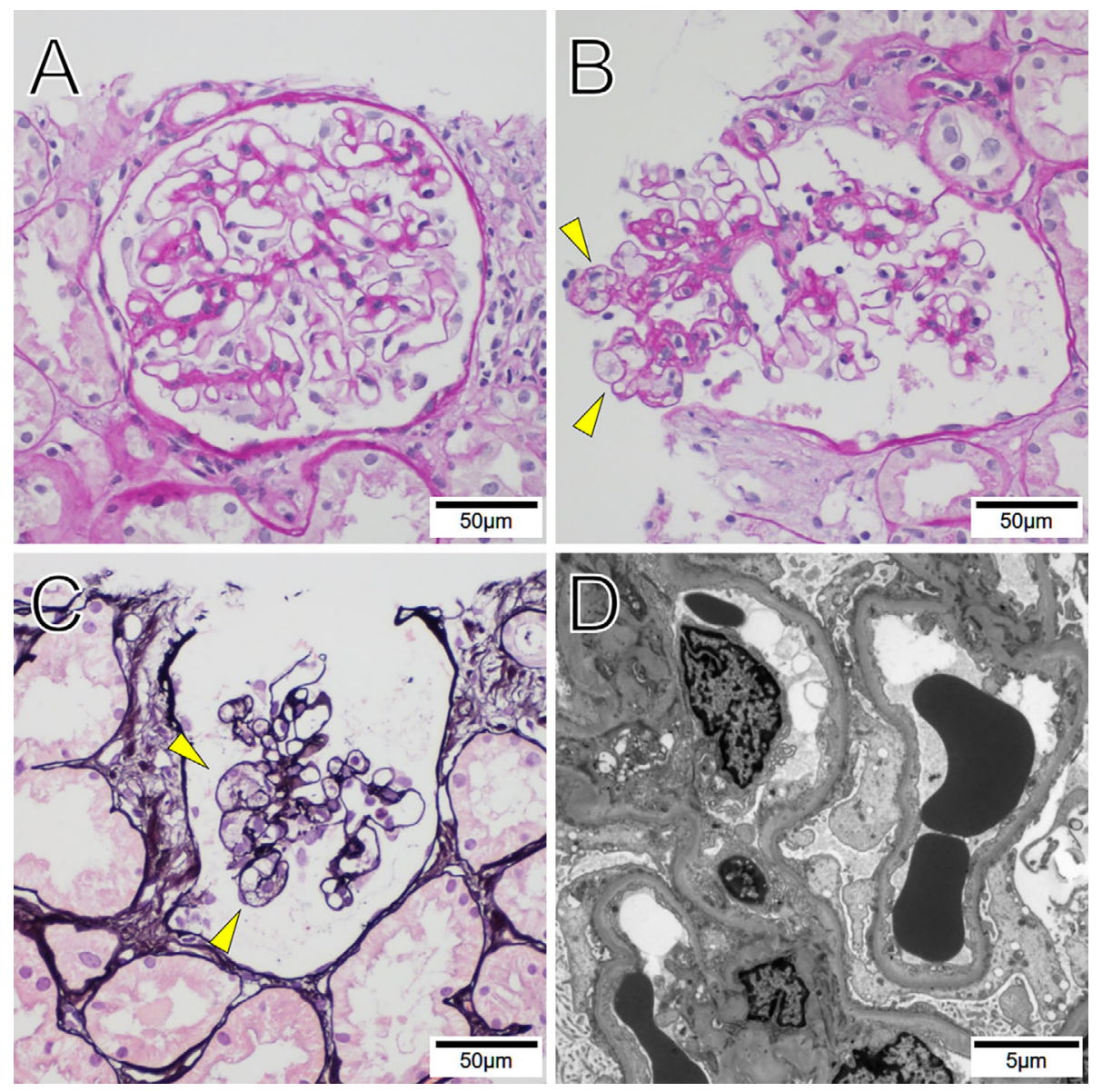

Figure 1. Histopathological findings in kidney biopsy specimen. A: Normal glomerulus (Periodic acid-Schiff stain, $\times 200$ ). B: Segmental infiltration of foam cells in glomerular capillaries (Periodic acid-Schiff stain, $\times 200)$. C: Segmental infiltration of foam cells in glomerular capillaries in another glomerulus (Periodic acid-methenamine-silver stain, $\times 200$ ). D: Extensive podocyte foot process effacement (electron microscopy). The arrowhead indicates endocapillary foam cell accumulation.

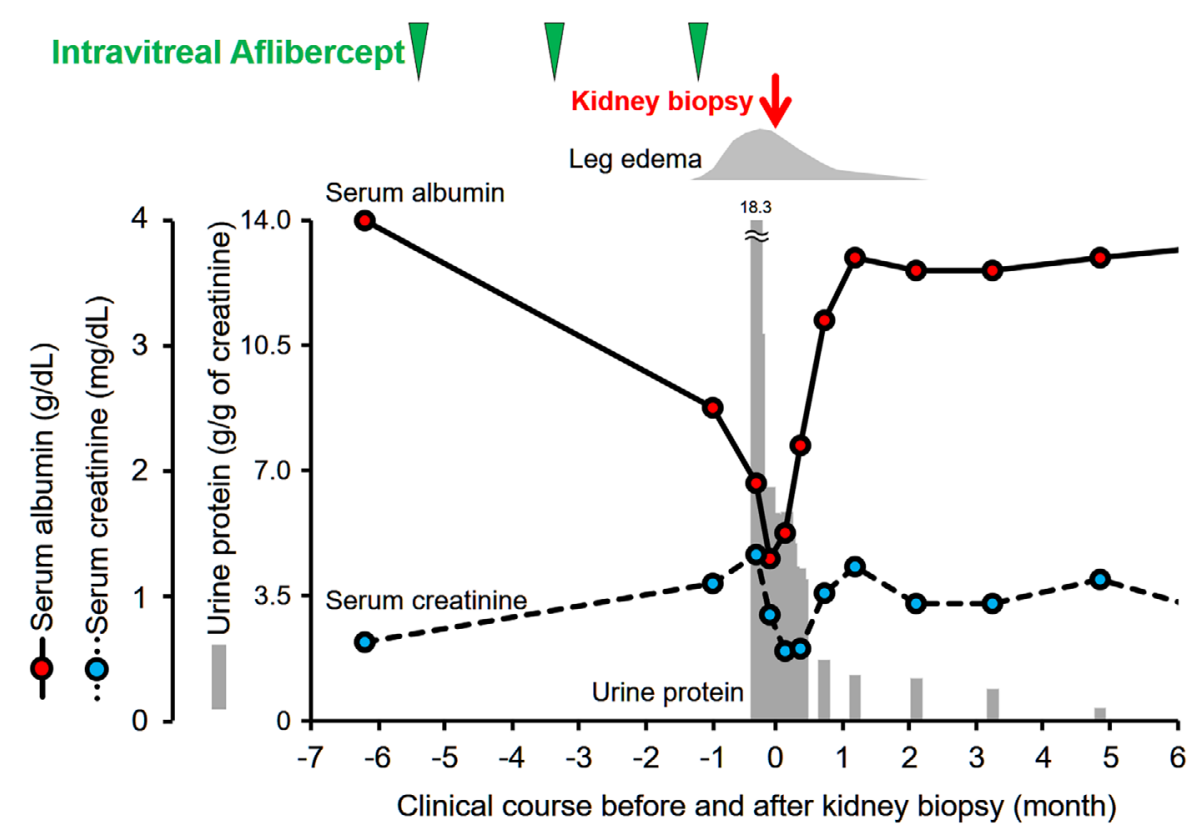

Figure 2. Clinical course. 
thrombotic micro-angiopathy. Injury of the podocyte, which also has a VEGF receptor, results in the structural deterioration of the podocyte foot and FSGS (6).

Given that the focal segmental infiltration of foam cells was compatible with the cellular variant according to the Columbia classification, we diagnosed this patient with FSGS. Relatively acute progression of nephrotic syndrome assisted in the diagnosis. The lack of diffuse endothelial injury and thrombotic lesions denied thrombotic microangiopathy.

\section{FSGS induced by intravitreal injections of aflibercept}

We suspected intravitreal injection of aflibercept as the main cause of FSGS in this case, given that her nephrotic syndrome resolved immediately following the termination of aflibercept therapy. Several authors previously reported the association of intravitreal injection of VEGF inhibitors with proteinuria (2), a reduction in the glomerular filtration rate (7), thrombotic micro-angiopathy (8), and minimal change disease (9). However, to our knowledge, this is the first report of intravitreal injection of aflibercept inducing FSGS. Most previous reports involved bevacizumab, another direct VEGF suppressor, and there have been few reports concerning aflibercept $(2,10)$.

It is hypothesized that even aflibercept injected into vitreous can be transferred into the systemic blood system particularly when the blood-retinal barrier is impaired due to immature choroidal neovascularization (11), as we observed. Of note, we were unable to confirm increased blood levels of aflibercept.

While FSGS may be a rare comorbidity, we should keep it in mind even when VEGF inhibitors are administered into the vitreous instead of systemically, and careful monitoring of proteinuria and the renal function should be conducted in such situations. When any comorbidities are found, a decrease in the dose or termination of the VEGF inhibitor altogether is recommended, and alternative therapeutic strategies for ocular diseases without VEGF inhibitors should be discussed (10). Switching to other VEGF inhibitors might be a viable strategy, although there have been no studies comparing the impact of different VEGF inhibitors injected into the vitreous on the kidney function. Risk factors and strategies for preventing renal injury during VEGF inhibitor in- travitreal injection therapy should be explored in future studies.

The authors state that they have no Conflict of Interest (COI).

\section{References}

1. Eremina V, Jefferson JA, Kowalewska J, et al. VEGF inhibition and renal thrombotic microangiopathy. N Engl J Med 358: 11291136, 2008.

2. Hanna RM, Lopez E, Hasnain H, et al. Three patients with injection of intravitreal vascular endothelial growth factor inhibitors and subsequent exacerbation of chronic proteinuria and hypertension. Clin Kidney J 12: 92-100, 2019.

3. Pham B, Thomas SM, Lillie E, et al. Anti-vascular endothelial growth factor treatment for retinal conditions: a systematic review and meta-analysis. BMJ Open 9: e022031, 2019.

4. Stewart MW. Aflibercept (VEGF Trap-eye): the newest anti-VEGF drug. Br J Ophthalmol 96: 1157-1158, 2012.

5. Zhu X, Wu S, Dahut WL, Parikh CR. Risks of proteinuria and hypertension with bevacizumab, an antibody against vascular endothelial growth factor: systematic review and meta-analysis. Am J Kidney Dis 49: 186-193, 2007.

6. Estrada CC, Maldonado A, Mallipattu SK. Therapeutic inhibition of VEGF signaling and associated nephrotoxicities. J Am Soc Nephrol 30: 187-200, 2019.

7. Georgalas I, Papaconstantinou D, Papadopoulos K, Pagoulatos D, Karagiannis D, Koutsandrea C. Renal injury following intravitreal anti-VEGF administration in diabetic patients with proliferative diabetic retinopathy and chronic kidney disease - a possible side effect? Curr Drug Saf 9: 156-158, 2014.

8. Pelle G, Shweke N, Duong Van Huyen JP, et al. Systemic and kidney toxicity of intraocular administration of vascular endothelial growth factor inhibitors. Am J Kidney Dis 57: 756-759, 2011.

9. Sato T, Kawasaki Y, Waragai T, et al. Relapse of minimal change nephrotic syndrome after intravitreal bevacizumab. Pediatr Int 55: e46-e48, 2013.

10. Hanna RM, Barsoum M, Arman F, Selamet U, Hasnain H, Kurtz I. Nephrotoxicity induced by intravitreal vascular endothelial growth factor inhibitors: emerging evidence. Kidney Int 96: 572580, 2019.

11. Avery RL, Castellarin AA, Steinle NC, et al. Systemic pharmacokinetics following intravitreal injections of ranibizumab, bevacizumab or aflibercept in patients with neovascular AMD. Br J Ophthalmol 98: 1636-1641, 2014.

The Internal Medicine is an Open Access journal distributed under the Creative Commons Attribution-NonCommercial-NoDerivatives 4.0 International License. To view the details of this license, please visit (https://creativecommons.org/licenses/ by-nc-nd/4.0/).

\footnotetext{
(C) 2020 The Japanese Society of Internal Medicine
} Intern Med 59: 3051-3054, 2020 